\title{
Características vegetativas, fenológicas e produtivas do pessegueiro cultivar Chimarrita enxertado em diferentes porta-enxertos
}

\author{
Luciano Picolotto(1), Roberta Manica-Berto(1), Dalcionei Pazin(1), Mateus da Silveira Pasa(1), Juliano Dutra Schmitz(1), \\ Marcos Ernani Prezotto(1), Débora Betemps ${ }^{(1)}$, Valmor João Bianchi( ${ }^{(1)}$ e José Carlos Fachinello(1)
}

\begin{abstract}
(1)Universidade Federal de Pelotas, Departamento de Fitotecnia, Caixa Postal 354, CEP 96010-900 Pelotas, RS. E-mail: picolotto@gmail.com, robertamanica@yahoo.com.br, dalcionei@hotmail.com, mateus_pasa@yahoo.com.br, jdsagro@gmail.com, marcosprezotto@hotmail.com, deborabetemps@yahoo.com.br, valmorjb@yahoo.com, jfachi@ufpel.tche.br
\end{abstract}

\begin{abstract}
Resumo - O objetivo deste trabalho foi avaliar o efeito de diferentes porta-enxertos no desenvolvimento vegetativo, fenológico e produtivo do pessegueiro [Prunus persica (L.) Batsch] cv. Chimarrita. Os portaenxertos utilizados foram 'Capdeboscq', 'Tsukuba 1', 'Okinawa', 'Aldrighi' e 'GF 305'. As variáveis analisadas foram: diâmetro do tronco, volume da copa, material retirado da poda, época de brotação, época de floração, quantidade de clorofila, área foliar específica, comprimento dos ramos principais, produtividade, massa dos frutos, coloração do fruto, firmeza de polpa, teor de sólidos solúveis totais (SST), acidez titulável (TA), relação SST/AT, fenóis totais e época de maturação. O delineamento experimental foi o de blocos ao acaso, com quatro repetições com cinco plantas cada. Não houve efeito dos porta-enxertos em: início da brotação, início da queda de folha, área foliar específica e maturação e massa de fruto. O diâmetro de tronco, comprimento de ramos, volume de copa, massa verde da poda e quantidade de clorofila foram influenciados mais pelos porta-enxertos 'Capdeboscq', 'Okinawa' e 'Tsukuba 1'. O maior número de flores por ramo foi obtido com o porta-enxerto 'Capdeboscq'. Frutos mais avermelhados foram produzidos com o porta-enxerto 'GF 305', e os vermelhoamarelados com 'Okinawa'.
\end{abstract}

Termos para indexação: Prunus, desenvolvimento, fenologia, floração, produtividade.

\section{Vegetative, phenological and productive characteristics of peach trees cultivar Chimarrita grafted on different rootstocks}

\begin{abstract}
The aim of this work was to evaluate the effect of different rootstocks on vegetative, phenological and productive development of peach trees [Prunus persica $(\mathrm{L}$.$) Batsch] cv. Chimarrita. The rootstocks used$ were 'Capdeboscq', 'Tsukuba 1', 'Okinawa', 'Aldrighi' and 'GF 305'. The variables studied were: trunk diameter, canopy volume, pruning weight, leafing and flowering time, chlorophyll content, leaf specific area, length of scaffold branches, fruit weight and color, fruit flesh firmness, total soluble solid (TSS) content, titratable acidity (TA), TSS/TA ratio, total phenols and fruit ripening time. The experiment was carried out using a randomized block design with four replicates, with five plants each. No effect of the rootstocks was verified on the beginning of leafing, and on leaf fall, leaf specific area, and fruit ripening and weight. The trunk diameter, length of branches, canopy volume, weight of the material removed by the pruning and chlorophyll content were better influenced by 'Capdeboscq', 'Okinawa' and 'Tsukuba 1'. The highest number of flowers per branch was obtained with the rootstock 'Capdeboscq'. 'GF 305' provided redder fruits and 'Okinawa' redder-yellow fruits.
\end{abstract}

Index terms: Prunus, development, phenology, flowering, yield.

\section{Introdução}

A fruticultura moderna baseia-se na utilização de porta-enxertos, cujo emprego possibilita o cultivo de inúmeras cultivares e espécies nos mais diversos climas e regiões. A muda enxertada carrega todas as características desejáveis, o que não sucede com mudas provenientes de sementes (Simão, 1998). De acordo com Rossi (2004) e Rocha (2006), o estudo de portaenxertos para a cultura do pessegueiro é recente no Brasil, enquanto nos países Europeus e nos Estados Unidos existem materiais selecionados para diversas condições de cultivo.

Os trabalhos de pesquisa foram iniciados em 1997, na Universidade Federal de Pelotas, com os porta-enxertos das cultivares Capdeboscq e Aldrighi, 
utilizadas na indústria conserveira, e os porta-enxertos introduzidos: Okinawa, Tsukuba, Flordaguard, Nemared, Nemaguard, GF 677, entre outros.

Os porta-enxertos mais usados são 'Capdeboscq' - em razão da facilidade de obtenção de caroços e facilidade de germinação (Chalfun \& Hoffmann, 1997) - e 'Aldrighi', por apresentar afinidade com a maioria das cultivares copas (Rossi, 2004). Atualmente, nessa região, os pomares comerciais de pessegueiro são constituídos por mudas cujo porta-enxerto é obtido por meio de sementes provenientes da indústria de conservas. Em sua grande maioria, esses porta-enxertos são compostos por misturas varietais de cultivares tardias, que não atendem às exigências mínimas de qualidade (Fachinello, 2000; Rocha, 2006).

Nas principais regiões produtoras de pêssego, são usados diferentes porta-enxertos em razão de condições específicas de clima e solo (Finardi, 2003). É indispensável o conhecimento das características bioagronômicas dos porta-enxertos atualmente disponíveis no mercado internacional, para que se faça a escolha apropriada (Loreti, 2008). Muitos porta-enxertos obtidos em outras zonas edafoclimáticas, adaptados a determinadas exigências, têm sido introduzidos e adaptados a determinadas áreas de cultivo, sem serem previamente testados ou sem, às vezes, se observar sua origem e o motivo de ter sido difundido (Araya, 2004). A avaliação precisa das respostas dos porta-enxertos, e a identificação da melhor combinação do enxerto com o porta-enxerto são importantes para se obterem produções de qualidade (Rato et al., 2008).

O que justifica o uso de porta-enxertos em fruticultura é a sua influência nas características vegeto-produtivas sobrea copa. Inúmeras pesquisas têm sido realizadas sobre esse tema nas principais regiões produtoras mundiais, e seus resultados são utilizados para a definição de linhas de pesquisa, nos programas de melhoramento de portaenxertos, e para a indicação segura para fruticultores e viveiristas (Loreti \& Massai, 1999).

Oefeito dos porta-enxertos no vigor, desenvolvimento, florescimento, frutificação, longevidade e adaptação das plantas a determinadas condições edáficas é indicação de que a produtividade tem relação com a cultivar copa e com o porta-enxerto (Araya, 2004). A influência dos porta-enxertos não ocorre somente no crescimento $\mathrm{e}$ desenvolvimento, mas também na qualidade do fruto (Giorgi et al., 2005).

As características vegeto-produtivas são importantes para a fruticultura moderna, que preconiza o adensamento de plantas. De acordo com Barbosa et al. (1994), o cultivo de pessegueiro em alta densidade vem sendo pesquisado e aperfeiçoado desde a década de 1970, com objetivo de reduzir os custos das operações de poda, raleio e colheita, para antecipar a entrada em produção das plantas e acelerar a obtenção da produtividade máxima dos pomares (Loreti, 2001).

Este trabalho teve por objetivo avaliar efeitos de diferentes porta-enxertos sobre o desenvolvimento vegetativo, fenológico e produtivo do pessegueiro [Prunus persica (L.) Batsch] cv. Chimarrita, na região Sul do Rio Grande do Sul.

\section{Material e Métodos}

O trabalho foi conduzido em campo, no Centro Agropecuário da Palma, no Pomar Didático Professor Antônio Rodrigues Duarte da Silva, pertencente à Faculdade de Agronomia Eliseu Maciel da Universidade Federal de Pelotas (FAEM/UFPel), Capão do Leão, RS. O pomar com a cultivar Chimarrita foi implantado em 2003, com espaçamento de $5 \times 1,5 \mathrm{~m}$, sobre porta-enxertos das cultivares Okinawa, Aldrighi, Capdeboscq, GF 305 e Tsukuba 1. Os portaenxertos foram propagados por sementes, e o manejo do pomar foi realizado de acordo com as normas de produção integrada para a cultura do pessegueiro.

As mensurações dos caracteres bioagronômicos foram realizadas durante o período produtivo de 2006 a 2008. Os parâmetros analisados foram: diâmetro do tronco, medido $10 \mathrm{~cm}$ acima do ponto de enxertia, no início do período vegetativo das plantas, em duas posições opostas, sempre no mesmo ponto da planta; comprimento dos ramos produtivos e principais e seu incremento em comprimento, registrados ao final do período vegetativo das plantas; massa fresca de ramos retirados pela poda; volume da copa, calculado conforme Rossi (2004), por meio da fórmula: $\mathrm{V}=[(\mathrm{L} / 2) \times(\mathrm{E} / 2) \times \mathrm{A} \times \pi] / 3$, em que $\mathrm{V}$ é o volume de copa, L é a distância entre os ramos principais, E é a espessura média dos ramos principais e A é a altura da copa; época de início da brotação (até 10\% das gemas vegetativas abertas) e de queda de folha; quantidade de clorofila, medida com o aparelho Konica Minolta, Chlorophyll Meter, SPAD-502; área foliar específica - superfície da folha/massa de matéria seca da folha; época de floração, em percentagem de flores abertas 
$(<10 \%)$, plena floração (50 a 70\%) e final da floração - com a queda das pétalas e densidade florífera em cada $25 \mathrm{~cm}$ de ramo -, calculadas por meio da fórmula (número total de flores abertas/comprimento do ramo produtivo) $\times 25$; produtividade; massa média de fruto; e coloração da epiderme do fruto, medida com colorímetro marca Minolta 300 (realizaram-se duas leituras na região equatorial do fruto; a leitura da cor foi feita em escala tridimensional e expressa pela luminosidade ou claridade (L); a direção da cor é indicada por "a" (verde a vermelho) e "b" (azul a amarelo), que possibilitam o cálculo da tonalidade da cor por meio do ângulo $\mathrm{h}^{\mathrm{o}}$, pela fórmula $\mathrm{h}^{\mathrm{o}}=$ tangente $^{-1} \mathrm{~b} / \mathrm{a}$ ); firmeza de polpa, avaliada com penetrômetro manual, com ponteira de $8 \mathrm{~mm}$, medida na região equatorial e em lados opostos de cada fruto; teor de sólidos solúveis totais (SST), determinado com refratômetro analógico portátil; acidez titulável (AT), avaliada conforme normas do Instituto Adolfo Lutz (Pregnolatto \& Pregnolatto, 1985); relação SST/ AT; conteúdo de fenóis totais, quantificado por meio de uma adaptação do método de Folin-Ciocalteau (Singleton \& Rossi Junior, 1965) (utilizou-se ácido gálico para a elaboração da curva padrão); e época da maturação. Nas análises de frutos foram utilizados 40 frutos, 100 folhas e 80 ramos de cada tratamento.

$\mathrm{O}$ delineamento experimental foi em blocos ao acaso, com quatro repetições, cada uma composta de cinco plantas. Foi feita a análise de variância e a comparação de médias (Duncan, $\mathrm{p} \leq 0,05$ ), com o programa estatístico Sanest (Zonta \& Machado, 1995).

\section{Resultados e Discussão}

A utilização de diferentes porta-enxertos influenciou o diâmetro do tronco, comprimento de ramo produtivo, comprimento dos ramos principais e volume de copa, o que afetou o desenvolvimento da planta. Em três anos de avaliação, os porta-enxertos que induziram maior diâmetro médio foram 'Okinawa', 'Capdeboscq' e 'Tsukuba 1' (Tabela 1). A superioridade no comprimento do ramo produtivo ocorreu com 'Tsukuba 1' (2006 e 2007), 'Capdeboscq' (2006) e 'GF 305' (2007). Nos ramos principais, o crescimento mais elevado foi com 'Capdeboscq', 'Tsukuba 1' e 'Okinawa'. O aumento de crescimento dos ramos principais, de 2007 para 2008, foi maior com o porta-enxerto 'GF 305'. No entanto, o crescimento no volume de copa foi superior com os porta-enxertos 'Capdeboscq' (2006 e 2007) e 'Tsukuba 1' (2007) (Tabela 2).

As variáveis de desenvolvimento vegetativo apresentaram maior vigor com a utilização dos portaenxertos 'Capdeboscq', 'Tsukuba 1' e 'Okinawa' e baixo vigor com 'Aldrighi' e 'GF 305'. Esses resultados são importantes na definição do manejo adequado ao portaenxerto utilizado, principalmente quanto à definição do espaçamento a se adotar e à possibilidade de adensamento do pomar. Rocha (2006) obteve resultados semelhantes quanto ao vigor nesses porta-enxertos, o que é indicação de haver um comportamento bem definido desses porta-enxertos em relação à cultivar Chimarrita. Os efeitos diferenciados dos porta-enxertos no desenvolvimento da cultivar copa Suncrest também foram verificados por Giorgi et al. (2005). Outro indicativo apresentado por esses porta-enxertos foi a maior necessidade de poda daqueles mais vigorosos, principalmente no 'Capdeboscq' (Tabela 2), fator importante que define o custo da prática de poda. É provável que o baixo desempenho do 'GF 305' esteja associado à maior suscetibilidade ao ataque de pragas, como os nematódeos-das-galhas, e às viroses, além de ser altamente exigente em condições de frio, pois em condições normais é citado como de hábito vigoroso

Tabela 1. Diâmetro do tronco, comprimento do ramo produtivo, comprimento dos ramos principais (CP, 2007 e 2008) e incremento dos ramos principais (IP, 2007 e 2008) da cultivar Chimarrita, enxertada sobre diferentes porta-enxertos ${ }^{(1)}$.

\begin{tabular}{|c|c|c|c|c|c|c|c|c|}
\hline \multirow[t]{2}{*}{ Cultivar } & \multicolumn{3}{|c|}{ Diâmetro de tronco (mm) } & \multicolumn{3}{|c|}{ Comprimento do ramo produtivo $(\mathrm{cm})$} & \multirow{2}{*}{$\begin{array}{c}\mathrm{CP} \\
(\mathrm{cm})\end{array}$} & \multirow{2}{*}{$\begin{array}{c}\mathrm{IP} \\
(\mathrm{cm})\end{array}$} \\
\hline & 2006 & 2007 & 2008 & 2006 & 2007 & 2008 & & \\
\hline Capdeboscq & $33,9 \mathrm{a}$ & $46,1 \mathrm{a}$ & $53,32 \mathrm{a}$ & $38,0 \mathrm{a}$ & $36,2 \mathrm{ab}$ & $30,4 \mathrm{ab}$ & $186,1 \mathrm{a}$ & $21,4 b$ \\
\hline Tsukuba 1 & $32,9 a$ & $44,2 \mathrm{a}$ & $52,80 \mathrm{ab}$ & $36,4 \mathrm{a}$ & $35,0 \mathrm{ab}$ & $34,5 \mathrm{a}$ & $180,1 \mathrm{a}$ & $23,9 b$ \\
\hline Okinawa & $34,2 \mathrm{a}$ & $43,8 \mathrm{ab}$ & $53,14 \mathrm{a}$ & $34,2 \mathrm{ab}$ & $32,7 \mathrm{~b}$ & $27,7 \mathrm{~b}$ & $175,3 \mathrm{a}$ & $23,4 b$ \\
\hline Aldrighi & $27,0 \mathrm{~b}$ & $39,3 b c$ & $47,69 \mathrm{bc}$ & $31,7 \mathrm{bc}$ & $34,6 b$ & $28,9 b$ & $152,5 b$ & $32,9 \mathrm{ab}$ \\
\hline GF 305 & $24,0 \mathrm{~b}$ & $37,7 \mathrm{c}$ & $46,62 \mathrm{c}$ & $29,3 \mathrm{c}$ & $39,1 \mathrm{a}$ & $29,9 b$ & $147,3 b$ & $40,9 \mathrm{a}$ \\
\hline CV (\%) & 30,4 & 13,5 & 50,6 & 15,6 & 15,6 & 15,6 & 12,7 & 6,7 \\
\hline
\end{tabular}

(1)Médias seguidas de letras iguais, nas colunas, não diferem entre si pelo teste de Duncan, a 5\% de probabilidade. 
(Loreti, 2008). No entanto, observou-se, pelo maior incremento no crescimento, que o 'GF 305' teve boa recuperação, mas não acompanhou o crescimento dos demais porta-enxertos.

O início da queda das folhas e da brotação não foi influenciado significativamente pelos porta-enxertos. Em 2008, o limite máximo estipulado de até $10 \%$ das gemas sem folhas foi observado na segunda quinzena do mês de fevereiro (26 de fevereiro) (Tabela 3). Essa característica pode ser importante para a manutenção da fotossíntese ativa em um período maior, o que favorece o maior acúmulo de reservas, necessário para a manutenção do estado nutricional das plantas durante o período hibernal e para a retomada da floração e brotação. $\mathrm{O}$ início da brotação ocorreu na segunda quinzena de julho, em ambos os anos avaliados. Em 2007 e 2008, pelo menos 80\% das plantas de cada tratamento iniciaram a brotação em 18 de julho (Tabela 3). A ausência de efeitos dos porta-enxertos sobre a queda de folhas e início de brotação indica que a entrada e a saída da dormência, segundo Petri \& Herter (2004), são influenciadas pela temperatura e controladas principalmente pela cultivar copa.

Houve diferença na quantidade de clorofila, cujos valores mais elevados foram verificados nas cultivares Okinawa, Capdeboscq e Tsukuba 1 (Tabela 3). Essas diferenças na quantidade de clorofila não foram verificadas por Zarrouk et al. (2005) ao estudar portaenxertos para as cultivares de pessegueiro Queen, Giant e Tebana.

Em relação à área foliar específica, os porta-enxertos não induziram diferenças significativas (Tabela 3), o que indica que o crescimento e desenvolvimento das folhas ocorrem na mesma época, em todos os portaenxertos testados. Segundo Monteiro et al. (2005), a variação temporal da área foliar em uma cultura agrícola depende das condições edafoclimáticas, da cultivar e da densidade populacional, entre outros fatores. Geralmente, a área foliar aumenta até um máximo e decresce após algum tempo, sobretudo em consequência da senescência das folhas mais velhas.

O início da floração ocorreu na segunda quinzena de julho, em ambos os anos avaliados, o que concorda com o descrito por Nienow \& Floss (2002); porém, em 2007, algumas flores abertas foram observadas no mês de maio. Um retardamento da floração ocorreu nos porta-enxertos 'Aldrighi' (2007) e 'Capdeboscq' (2008), e uma antecipação no 'GF 305' (2008). A plena floração ocorreu na primeira quinzena do mês de agosto em 2007, e a maior percentagem de flores abertas (avaliação em 8 de agosto) ocorreu com os porta-enxertos 'Tsukuba 1' (64\%), 'Capdeboscq' (60\%),

Tabela 2. Volume da copa, massa da poda, número de gemas floríferas em cada $25 \mathrm{~cm}$ de ramo, gemas floríferas dormentes (GD, 2008) e início da floração da cultivar Chimarrita, enxertada sobre diferentes porta-enxertos ${ }^{(1)}$.

\begin{tabular}{|c|c|c|c|c|c|c|c|c|c|}
\hline \multirow[t]{2}{*}{ Cultivar } & \multicolumn{2}{|c|}{ Volume da copa $\left(\mathrm{m}^{3}\right)$} & \multicolumn{2}{|c|}{ Massa da poda (g) } & \multicolumn{2}{|c|}{ Número de gemas floríferas } & \multirow[t]{2}{*}{ GD (\%) } & \multicolumn{2}{|c|}{ Início da floração } \\
\hline & 2006 & 2007 & 2006 & 2007 & 2006 & 2007 & & 2007 & 2008 \\
\hline Capdeboscq & $1,4 \mathrm{a}$ & $2,2 \mathrm{a}$ & $2.922 \mathrm{a}$ & $2.499 \mathrm{a}$ & $18,3 \mathrm{a}$ & $13,8 \mathrm{a}$ & $41 \mathrm{a}$ & $18-27 / 7$ & $23-29 / 7$ \\
\hline Tsukuba 1 & $1,3 \mathrm{ab}$ & $2,1 \mathrm{a}$ & $2.593 \mathrm{~b}$ & $2.081 \mathrm{~b}$ & $13,6 b c$ & $16,1 \mathrm{a}$ & $27 \mathrm{~b}$ & $18-27 / 7$ & $18-23 / 7$ \\
\hline Okinawa & $1,1 \mathrm{ab}$ & $2,0 \mathrm{ab}$ & $2.535 \mathrm{~b}$ & $2.182 b$ & $16,6 a b$ & $13,3 \mathrm{a}$ & $20 \mathrm{~b}$ & $18-27 / 7$ & $18 / 7$ \\
\hline Aldrighi & $1,0 \mathrm{bc}$ & $1,5 \mathrm{bc}$ & $1.989 \mathrm{c}$ & $1.828 \mathrm{c}$ & $13,8 \mathrm{bc}$ & $14,9 \mathrm{a}$ & $23 b$ & $27 / 7-2 / 8$ & $18-23 / 7$ \\
\hline GF 305 & $0,7 \mathrm{c}$ & $1,5 \mathrm{c}$ & $1.301 \mathrm{~d}$ & $2.172 b$ & $11,1 \mathrm{c}$ & $12,7 \mathrm{a}$ & $4 \mathrm{c}$ & $18-27 / 7$ & $24 / 7-18 / 8$ \\
\hline $\mathrm{CV}(\%)$ & 34,2 & 30,4 & 6,7 & 6,7 & 28,5 & 28,5 & 64,7 & - & - \\
\hline
\end{tabular}

${ }^{(1)}$ Médias seguidas de letras iguais, nas colunas, não diferem entre si pelo teste de Duncan, a 5\% de probabilidade.

Tabela 3. Gemas sem folha (em 2008), quantidade de clorofila (em 2007), área foliar específica (em 2007), plantas com brotação e produtividade da cultivar Chimarrita, enxertada sobre diferentes porta-enxertos ${ }^{(1)}$.

\begin{tabular}{|c|c|c|c|c|c|c|c|c|}
\hline \multirow[t]{2}{*}{ Cultivar } & \multirow{2}{*}{$\begin{array}{l}\text { Gemas sem } \\
\text { folha }(\%)\end{array}$} & \multirow[t]{2}{*}{ Clorofila } & \multirow{2}{*}{$\begin{array}{l}\text { Área foliar específica } \\
\qquad\left(\mathrm{cm}^{2} \mathrm{mg}^{-1}\right)\end{array}$} & \multicolumn{2}{|c|}{ Plantas com brotacão (\%) } & \multicolumn{3}{|c|}{ Produtividade $\left(\mathrm{Mg} \mathrm{ha}^{-1}\right)$} \\
\hline & & & & $18 / 7 / 2007$ & $18 / 7 / 2008$ & 2006 & 2007 & 2008 \\
\hline Capdeboscq & $5,0 \mathrm{a}$ & $35,9 \mathrm{a}$ & $133,2 \mathrm{a}$ & $100 \mathrm{a}$ & $100 \mathrm{a}$ & $5,8 \mathrm{a}$ & $16,1 \mathrm{a}$ & $3,1 \mathrm{~b}$ \\
\hline Okinawa & $10,0 \mathrm{a}$ & $36,2 \mathrm{a}$ & $130,9 \mathrm{a}$ & $82 \mathrm{a}$ & $100 \mathrm{a}$ & $4,7 \mathrm{ab}$ & $15,8 \mathrm{a}$ & $6,2 \mathrm{ab}$ \\
\hline Tsukuba 1 & $10,0 \mathrm{a}$ & $35,9 \mathrm{a}$ & $130,0 \mathrm{a}$ & $100 \mathrm{a}$ & $100 \mathrm{a}$ & $4,6 a b$ & $15,1 \mathrm{a}$ & $5,8 \mathrm{ab}$ \\
\hline Aldrighi & $5,0 \mathrm{a}$ & $34,5 \mathrm{~b}$ & $136,4 \mathrm{a}$ & $100 \mathrm{a}$ & $85 \mathrm{a}$ & $3,9 \mathrm{~b}$ & $12,6 \mathrm{~b}$ & $3,5 \mathrm{~b}$ \\
\hline GF 305 & $10,0 \mathrm{a}$ & $34,7 \mathrm{~b}$ & $136,7 \mathrm{a}$ & $82 \mathrm{a}$ & $100 \mathrm{a}$ & $1,9 \mathrm{c}$ & $8,0 \mathrm{c}$ & $7,3 \mathrm{a}$ \\
\hline$\overline{C V}(\%)$ & 4,2 & 6,2 & 6,0 & 13,6 & 13,6 & 17,7 & 17,7 & 45,1 \\
\hline
\end{tabular}

${ }^{(1)}$ Médias seguidas de letras iguais, nas colunas, não diferem entre si pelo teste de Duncan, a 5\% de probabilidade. 
'GF 305' (60\%), 'Aldrighi' (59\%) e 'Okinawa' (45\%). Em 2008, a plena floração ocorreu entre o final de julho e início de agosto, em avaliação realizada em 5 de agosto, e a maior percentagem de flores abertas ocorreu com o porta-enxerto 'GF 305' (86\%), seguido 'Okinawa' (63\%), 'Aldrighi' (51\%), 'Tsukuba 1' (55\%) e 'Capdeboscq' (36\%). A baixa percentagem de flores no porta-enxerto 'Capdeboscq', em 2008, não tem causa definida, no entanto, um grande número de ramos secos foram observados, o que é indicação de algum distúrbio fisiológico. Apesar de variar com os diferentes porta-enxertos, a floração ocorreu dentro do período descrito para a cultivar copa Chimarrita (Nienow \& Floss, 2002).

$\mathrm{Na}$ densidade florífera avaliada em 2006 e 2007, houve diferença significativa somente em 2006; a maior densidade de flores foi observada no porta-enxerto 'Capdeboscq' e a menor, no 'GF 305' (Tabela 2).

A produtividade foi influenciada significativamente pelas cultivares de porta-enxertos, tendo sido maior com 'Capdeboscq' (5,8 Mg ha-1 em 2006 e 16,1 $\mathrm{Mg} \mathrm{ha}^{-1}$ em 2007), seguida de 'Okinawa' (15,8 $\mathrm{Mg} \mathrm{ha}^{-1} \mathrm{em}$ 2007), 'Tsukuba 1' (15,1 $\left.\mathrm{Mg} \mathrm{ha}^{-1} \mathrm{em} 2007\right)$, 'GF 305' (7,3 $\mathrm{Mg} \mathrm{ha}^{-1}$ em 2008), 'Aldrighi' (3,9 $\mathrm{Mg} \mathrm{ha}^{-1} \mathrm{em}$ 2006 e 3,5 $\mathrm{Mg} \mathrm{ha}^{-1}$ em 2008) e 'GF 305' (1,9 $\mathrm{Mg} \mathrm{ha}^{-1}$ em 2006 e $8 \mathrm{Mg} \mathrm{ha}^{-1}$ em 2007). É provável que a baixa produtividade no ano de 2008 esteja associada, principalmente, à ocorrência de temperaturas altas no período de dormência das plantas, o que também pode ter prejudicado a floração, pois ocasionou uma quantidade maior de gemas floríferas dormentes em alguns porta-enxertos (Tabela 2). Também foram verificados bons desempenhos dos porta-enxerto 'Okinawa' na cultivar Chimarrita (Rocha, 2006) e 'Tsukuba 1' na cultivar Granada (Rossi, 2004). Em 2008, os porta-enxertos parecem não ter expressado todo seu potencial produtivo, fato verificado pelo grande número de flores dormentes (Tabela 2), provavelmente em razão das condições adversas de temperatura na época da floração. Essa diferença de produtividade, no entanto, pode ter relação com a variação de carboidratos disponíveis, responsáveis pela formação das gemas floríferas (Simão, 1998).

A massa média dos frutos não foi influenciada pelos diferentes porta-enxertos (Tabela 4), semelhantemente ao verificado por Giacobbo et al. (2003), ao testar diferentes espaçamentos entre plantas, na cultivar Chimarrita. Porém, não concorda com o descrito por Rocha (2006) e Remorini et al. (2008).

No entanto, foram verificadas diferenças significativas na coloração do fruto. No porta-enxerto 'GF 305', a cor foi mais avermelhada (Tabela 4). Enquanto nas cultivares Okinawa, Capdeboscq e Tsukuba 1, a coloração dos frutos foi mais amarelada. Essa coloração menos intensa do vermelho e mais intensa do amarelo gerou o ângulo $\mathrm{h}^{\circ}$ ou tonalidade maior com a 'Okinawa'. Quanto à luminosidade, verificou-se fruto mais claro na cultivar Okinawa, seguida de Capdeboscq, Tsukuba 1 e GF 305. A coloração mais vermelha do 'GF 305' tem relação, provavelmente, com a maior iluminação no interior da planta, em razão de seu menor tamanho, o que é importante para a melhora da coloração da película dos frutos (Hadlich \& Marodin, 2004).

Entre os indicadores de maturação, a firmeza de polpa, sólidos solúveis totais e acidez titulável tiveram algumas diferenças significativas entre os portaenxertos. Quanto à firmeza de polpa, verificaram-se frutos mais firmes com os porta-enxertos 'GF 305' e 'Adrighi' (Tabela 5). Valor menor de firmeza de polpa (8,09 libras) foi observado em frutos maduros firmes por Kaster et al. (1998) na cultivar Chimarrita, diferentemente de Rocha (2006), que encontrou valores entre 12 a 14 libras. Estudos realizados por Giorgi et al. (2005) e Remorini et al. (2008) também mostraram o

Tabela 4. Massa média de fruto (g), coloração de fruto [luminosidade (L), direção do vermelho/verde (A), direção do amarelo/ azul (B) e tonalidade da cor $\left(\mathrm{h}^{\circ}\right)$ ] na região equatorial superior direita e pico de maturação da cultivar Chimarrita, enxertada sobre diferentes porta-enxertos ${ }^{(1)}$.

\begin{tabular}{|c|c|c|c|c|c|c|c|}
\hline \multirow[t]{2}{*}{ Cultivar } & \multirow[t]{2}{*}{ Massa de fruto (2006 e 2007) } & \multicolumn{4}{|c|}{ Coloração de fruto (2007 e 2008) } & \multicolumn{2}{|c|}{ Pico de maturação (\%) } \\
\hline & & $\mathrm{L}$ & $\mathrm{A}$ & $\mathrm{B}$ & $h^{0}$ & $27 / 11 / 2006$ & $27 / 11 / 2007$ \\
\hline Okinawa & $115,9 \mathrm{a}$ & $51,8 \mathrm{a}$ & $13,0 \mathrm{~b}$ & $28,3 \mathrm{a}$ & $62,5 \mathrm{a}$ & $54,0 \mathrm{~b}$ & $35,0 \mathrm{a}$ \\
\hline Capdeboscq & $119,2 \mathrm{a}$ & $51,2 \mathrm{a}$ & $13,5 \mathrm{ab}$ & $27,4 a$ & $60,7 \mathrm{ab}$ & $54,0 \mathrm{~b}$ & $39,0 \mathrm{a}$ \\
\hline Tsukuba 1 & $104,4 \mathrm{a}$ & $50,8 \mathrm{ab}$ & $14,0 \mathrm{ab}$ & $27,8 \mathrm{a}$ & $60,2 \mathrm{ab}$ & $57,0 \mathrm{ab}$ & $41,0 \mathrm{a}$ \\
\hline GF 305 & $128,5 \mathrm{a}$ & $48,5 \mathrm{ab}$ & $17,3 \mathrm{a}$ & $24,3 b$ & $53,8 \mathrm{bc}$ & $54,0 \mathrm{~b}$ & $40,0 \mathrm{a}$ \\
\hline Aldrighi & $105,6 \mathrm{a}$ & $47,6 \mathrm{~b}$ & $16,2 \mathrm{ab}$ & $26,6 b$ & $53,0 \mathrm{c}$ & $60,0 \mathrm{a}$ & $40,0 \mathrm{a}$ \\
\hline $\mathrm{CV}(\%)$ & 35,0 & 14,6 & 3,4 & 20,5 & 26,2 & 4,3 & 27,0 \\
\hline
\end{tabular}

${ }^{(1)}$ Médias seguidas de letras iguais, nas colunas, não diferem entre si pelo teste de Duncan, a $5 \%$ de probabilidade. 
Tabela 5. Firmeza de polpa (FP), sólidos solúveis totais (SST), acidez titulável (AT), relação SST/AT e fenóis totais da cultivar Chimarrita, enxertada sobre diferentes porta-enxertos, no ciclo produtivo $2007^{(1)}$.

\begin{tabular}{lccccc}
\hline Cultivar & $\begin{array}{c}\text { FP } \\
(\mathrm{lb})\end{array}$ & $\begin{array}{c}\text { SST } \\
\left({ }^{\circ} \text { Brix }\right)\end{array}$ & $\begin{array}{c}\text { AT } \\
(\% \text { ác. cítrico })\end{array}$ & SST/AT & Fenóis $^{(2)}$ \\
\hline GF 305 & $11,7 \mathrm{a}$ & $10,4 \mathrm{a}$ & $0,295 \mathrm{a}$ & $35,1 \mathrm{~b}$ & $85,41 \mathrm{a}$ \\
Aldrighi & $11,5 \mathrm{a}$ & $9,8 \mathrm{~b}$ & $0,285 \mathrm{a}$ & $34,5 \mathrm{~b}$ & $59,52 \mathrm{~b}$ \\
Okinawa & $9,2 \mathrm{~b}$ & $10,7 \mathrm{a}$ & $0,270 \mathrm{ab}$ & $39,3 \mathrm{ab}$ & $38,09 \mathrm{~d}$ \\
Tsukuba 1 & $8,6 \mathrm{bc}$ & $10,5 \mathrm{a}$ & $0,248 \mathrm{bc}$ & $42,6 \mathrm{a}$ & $41,00 \mathrm{c}$ \\
Capdeboscq & $7,1 \mathrm{c}$ & $9,8 \mathrm{~b}$ & $0,235 \mathrm{c}$ & $42,0 \mathrm{a}$ & $34,40 \mathrm{e}$ \\
\hline CV $(\%)$ & 47,0 & 13,1 & 8,2 & 10,3 & 5,1 \\
\hline
\end{tabular}

${ }^{(1)}$ Médias seguidas de letras iguais, nas colunas, não diferem entre si pelo teste de Duncan, a $5 \%$ de probabilidade ${ }^{(2)}$ Resultados expressos em miligramas de equivalente de ácido gálico por $100 \mathrm{~g}$ de amostra.

papel fundamental do porta-enxerto nesse índice de maturação. De acordo com Argenta et al. (2004), esse índice pode variar com o tamanho dos frutos, condições climáticas e práticas culturais e é maior, geralmente, em regiões mais secas e frias.

Quanto ao teor de sólidos solúveis dos frutos, os valores mais expressivos foram obtidos com a utilização dos porta-enxertos 'Okinawa', 'Tsukuba 1' e 'GF 305', que diferiram de 'Aldrighi' e 'Capdeboscq' (Tabela 5). Os resultados do presente trabalho foram menores que os de Giacobbo et al. (2003) e Rocha (2006). No entanto, nos estudos de Giorgi et al. (2005), os sólidos solúveis não foram afetados com o uso de diferentes porta-enxertos ('Barrier 1', 'Citation' 'GF677', 'Ishtara' e 'Julior'). Os SST podem variar com fatores como ano, região de produção e manejo do pomar (Argenta et al., 2004).

Quanto à acidez titulável, os valores mais elevados foram obervados nos porta-enxertos 'GF 305', 'Aldrighi' e 'Okinawa' (Tabela 5), semelhantes à verificada por Kaster et al. (1998) com a cultivar Chimarrita. Essa variação pode indicar maturação mais tardia, mas para Kluge et al. (2002), esse parâmetro é pouco confiável, em razão da pouca variação dessa característica durante a maturação. No presente trabalho, os portaenxertos apresentaram relação SST/AT, responsável pelo gosto do fruto, com valores menores. No entanto, esses valores foram altos se comparados aos de outras cultivares, como, por exemplo, Jubileu e Eldorado com 22 e 20 de relação SST/AT, respectivamente (Manica-Berto, 2008).

Os fenóis totais apresentaram diferenças entre os porta-enxertos; a maior quantidade destes compostos ocorreu com 'GF 305' (Tabela 5). Variações nos fenóis totais foram verificados em porta-enxertos de pessegueiro também por Giorgi et al. (2005) e Remorini et al. (2008). Combinações de fenóis tendem a se acumular no tecido epidérmico de plantas como forma de proteção contra a radiação (Dixon \& Paiva, 1995), o que pode causar distúrbios fisiológicos no armazenamento, como, por exemplo, o escurecimento interno (Martins et al., 2004). A época de maturação foi semelhante entre os porta-enxertos. Em 2006 e 2007, o pico da maturação ocorreu na última semana do mês de novembro (Tabela 4). Esse comportamento parece não ser igual em todos os porta-enxertos, já que Giorgi et al. (2005) verificaram precocidade na maturação em alguns dos porta-enxertos.

\section{Conclusões}

1. O desenvolvimento vegetativo da cultivar de pêssego Chimarrita é influenciado pelos porta-enxertos de maior vigor, como 'Capdeboscq', 'Tsukuba 1' e 'Okinawa'.

2. A qualidade dos frutos quanto à relação sólidos solúveis totais/acidez titulável, tonalidade da cor, firmeza de polpa e teor de fenóis totais é alterada pelos porta-enxertos 'Capdeboscq', 'Tsukuba 1' e 'Okinawa', de maior vigor.

3. A fenologia na cultivar Chimarrita é pouco influenciada pelos porta-enxertos.

4. A produtividade é modificada pelos porta-enxertos 'Capdeboscq', 'Tsukuba 1' e 'Okinawa'.

\section{Referências}

ARAYA, C.A.G. Efecto de diferentes portainjertos de cerezo sobre el comportamiento fenológico de los cultivares Lapins, Bing y Sweetheart, en San Francisco de Mostazal (VI Región). 2004. 105p. Tese (Mestrado) - Escuela de Agronomía Pontificia Universidad Católica de Valparaíso, Valparaíso.

ARGENTA, L.C.; CANTILLANO, F.F.; BECKER, W.D. Tecnologia pós-colheita para fruteiras de caroço. In: MONTEIRO, L.B.; MIO, L.L.M. de; SERRAT, B.M.; MOTTA, A.C.; CUQUEL, F.L. 
Fruteiras de caroço: uma visão ecológica. Curitiba: UFPR, 2004. p.333-367.

BARBOSA, W.; CAMPO-DALL'ORTO, F.A.; OJIMA, M.; LOVATE, A.A. O pessegueiro no sistema de pomar compacto: VII. Comportamento de novas seleções IAC sob poda drástica bienal. Scientia Agricola, v.51, p.94-98, 1994.

CHALFUN, N.N.J.; HOFFMANN, A. Propagação de pessegueiro e ameixeira. Revista Informativo Agropecuário, v.18, p.23-29, 1997.

DIXON, R.A.; PAIVA, N.L. Stress-induced phenylpropanoid metabolism. Plant Cell, v.7, p.1085-1097, 1995.

FACHINELLO, J.C. Problemática das mudas de plantas frutíferas de caroço. In: SIMPÓSIO INTERNACIONAL DE FRUTAS DE CAROÇO: PÊSSEGOS, NECTARINAS E AMEIXAS, 1., 2000, Porto Alegre. Anais. Porto Alegre: UFRGS, 2000. p.25-40.

FINARDI, N.L. Descrição e método de propagação de porta-enxerto. In: RASEIRA, M. do C.B.; CENTELLAS-QUEZADA, A. (Ed.). Pêssego: produção. Brasília: Embrapa Informação Tecnológica, 2003. p.60-70.

GIACOBBO, C.L.; FARIA, J.L.C.; CONTO, O. de; BARCELLOS, R.F. de; GOMES, F.R.C. Comportamento do pessegueiro [Prunus persica (L.) Batsch] cv. Chimarrita em diferentes sistemas de condução. Revista Brasileira de Fruticultura, v.25, p.242-244, 2003.

GIORGI, M.; CAPOCASA, F.; SCALZO, J.; MURRI, G.; BATTINO, M.; MEZZETTI, B. The rootstock effects on plant adaptability, production, fruit quality, and nutrition in the peach (cv. Suncrest). Scientia Horticulturae, v.107, p.36-42, 2005.

HADLICH, E.; MARODIN, G.A.B. Poda e condução do pessegueiro e da ameixeira. In: MONTEIRO, L.B.; MIO, L.L.M. de; SERRAT, B.M.; MOTTA, A.C.; CUQUEL, F.L. Fruteiras de caroço: uma visão ecológica. Curitiba: UFPR, 2004. p.97-117.

KASTER, L.C.; TREPTOW, R.O.; CAMELATTO, D. Qualidade de pêssegos [Prunus persica (L.) Batsch] frigorificados cv. Chiripá em dois estádios de maturação. In: CONGRESSO ARGENTINO DE ENGENHARIA RURAL, 5.; CONGRESSO LATINOAMERICANO DE ENGENHARIA RURAL, 2., 1998, Cidade de la Plata. Anais. La Plata: Universidade Nacional de La Plata, 1998. v.1, p.426-432.

KLUGE, R.A.; NACHTIGAL， J.C.; FACHINELLO, J.C.; BILHALVA, A.B. Fisiologia e manejo pós-colheita de frutas de clima temperado. 2.ed. Campinas: Rural, 2002. 214p.

LORETI, F. Formas atuais de condução e densidade de plantio do pessegueiro na Itália. In: ENCONTRO NACIONAL SOBRE FRUTICULTURA DE CLIMA TEMPERADO, 4., 2001, Fraiburgo. Anais. Caçador: Epagri, 2001. p.133-142.

LORETI, F. Porta-enxertos para a cultura do pessegueiro do terceiro milênio. Revista Brasileira de Fruticultura, v.30, p.274-284, 2008.

LORETI, F.; MASSAI, R. I portinnesti del pesco. L'Informatore Agrario, n.9, p.39-44, 1999.

MANICA-BERTO, R. Influência da interenxertia e dos sistemas de condução nas propriedades funcionais do pêssego. 2008. 50p. Dissertação (Mestrado) - Universidade Federal de Pelotas, Pelotas.

MARTINS, C.R.; CANTILLANO, R.F.F.; FARIAS, R. de M.; ROMBALDI, C.V. Atividade polifenoloxidase e compostos fenólicos em pós-colheita de pêssego cultivado em pomar com cobertura vegetal e cultivo tradicional. Ciência Rural, v.34, p.749-754, 2004.

MONTEIRO, J.E.B.A.; SENTELHAS, P.C.; CHIAVEGATO, E.J.; GUISELINI, C.; SANTIAGO, A.V.; PRELA, A. Estimação da área foliar do algodoeiro por meio de dimensões e massa das folhas. Bragantia, v.64, p.15-24, 2005.

NIENOW, A.A.; FLOSS, L.G. Floração de pessegueiros e nectarineiras no Planalto Médio do Rio Grande do Sul, influenciada pelas condições meteorológicas. Ciência Rural, v.32, p.931-936, 2002.

PETRI, J.L.; HERTER, F.G. Dormência e indução à brotação. In: MONTEIRO, L.B.; MIO, L.L.M. de; SERRAT, B.M.; MOTTA, A.C.; CUQUEL, F.L. Fruteiras de caroço: uma visão ecológica. Curitiba: UFPR, 2004. p.119-127.

PREGNOLATTO, W.; PREGNOLATTO, N.P. (Coord.). Normas analíticas do Instituto Adolfo Lutz: métodos químicos e físicos para análise de alimentos. 3.ed. São Paulo: Instituto Adolfo Lutz, 1985. v.1.553p.

RATO, A.E.; AGULHEIRO, A.C.; BARROSO, J.M.; RIQUELME, F. Soil and rootstock influence on fruit quality of plums (Prunus domestica L.). Scientia Horticulturae, v.118, p.218-222, 2008.

REMORINI, D.; TAVARINI, S.; DEGL'INNOCENTI, E.; LORETI, F.; MASSAI, R.; GUIDI, L. Effect of rootstocks and harvesting time on the nutritional quality of peel and flesh of peach fruits. Food Chemistry, n.110, p.361-367, 2008.

ROCHA, M.D.S. Comportamento fenológico e produtivo das cultivares de pessegueiro Chimarrita e Granada em diferentes porta-enxertos, nos três primeiros anos de implantação. 2006. 168p. Tese (Doutorado) - Universidade Federal de Pelotas, Pelotas.

ROSSI, A. Avaliação bioagronômica de pessegueiro 'Granada' e 'Suncrest' sobre diferentes porta-enxertos. 2004. 76p. Tese (Doutorado) - Universidade Federal de Pelotas, Pelotas.

SIMÃO, S. Tratado de fruticultura. Piracicaba: Fealq, 1998. $760 \mathrm{p}$.

SINGLETON, V.L.; ROSSI JUNIOR, J.A. Colorimetry of total phenolics with phosphomolybdic-phosphotungstic acid reagents. American Journal of Enology and Viticulture, v.16, p.144-158, 1965.

ZARROUK, O.; GOGORCENA, Y.; GÓMEZ-APARISI, J.; BETRÁN, J.A.; MORENO, M.A. Influence of almond x peach hybrids rootstocks on flower and leaf mineral concentration, yield and vigour of two peach cultivars. Scientia Horticulturae, v.106, p.502-514, 2005.

ZONTA, E.P.; MACHADO, A.A. SANEST: sistema de análise estatística para microcomputadores. Pelotas: UFPel, 1995. 48p.

$\overline{\text { Recebido em } 23 \text { de fevereiro de } 2009 \text { e aprovado em } 29 \text { de maio de } 2009}$ 